\title{
FUNCTIONS OF LOGISTICS SUPPORT MANAGEMENT FOR MILITARY ACTIVITIES DURING PEACE
}

\author{
Sorin PÎNZARIU \\ "Nicolae Bălcescu” Land Forces Academy, Sibiu, Romania \\ sorinpinz@yahoo.com \\ Costel-Dorel MÎNEA \\ Ministry of National Defence, Bucharest, Romania \\ robert02121971@yahoo.com
}

\begin{abstract}
The functions of logistics management for military activities during the peacetime are determinant for the realistic forecasts, computation, estimates, the opportunity of good decisions, the reliability and logical achieving of suitable logistics support for specific military activities and military exercises. Uniformly application of these functions, lead to timely necessary corrections in order to achieve the desired goals of logistics support for military activities on peacetime. Also, through the use of logistics management functions, we evaluate the results by comparing it in a matrix what we intended to achieve and was the final accomplishment. According to this matrix we can conclude positive and negative elements that influence the logistic support.
\end{abstract}

KEYWORDS: management, logistics, logistics management functions, logistics support

\section{Introduction}

The great challenges of the $21 \mathrm{st}$ century are closely linked to the global threat posed by terrorism to civilized states, the possible use of weapons of mass destruction, and the persistence of outbreaks of instability in the various regions of the world. These factors can generate tensions, crises and conflicts that, by their implications, can directly affect the interests of Romania and subsequently North Atlantic Treaty Organization (NATO) as well.

The development of society, the new content of relations between states, technology state of the art, the experience of military thinking and practice, the new shape of war, the updated features and requirements for the armed conflicts are the key factors acting as a blueprint, for developing of operational management, closely linked to the evolution of logistics support management.

Logistics support management for military activities on peace highlights the mandatory implementation of the specific management process, integrated within the military organization. The logistics management process is explained by the action of the leading subsystem on the driven subsystem as an outcome of the activities (foresight, decision, organization, command and control - evaluation) developed by the heads of the logistics 
modules in order to establish and achieve the specific objectives (supply, movement and transport, maintenance, etc.) during the military activities on peacetime. In fact, all these actions reflect the functions or attributes of logistics management which, if there are effectively applied, represents the base training of logistics support units for the real missions in emergencies, mobilization and war situations.

The logistics support management process has a cyclic character and is carried out in stages. This process begins with the setting of mission objectives for each military unit and ends with the final evaluation of the results. At each stage, the management system of logistics support performes a set of relatively independent actions that change successively. This succession of actions is called management functions.

\section{Logistic Support Management}

\section{Functions}

In this respect, Nicolescu and Verboncu (1997), as well as other authors, speaks about five functions, related to the type of tasks involved in carrying out these processes and their way of accomplishment, as follows: "forecasting, organization, coordination, training and controlevaluation" (p. 19).

Taking into account the close connection between the logistics planning and management bodies with the designated units for execution, we can define the functions of the logistics support management as a set of relatively independent actions that succeed in a certain timely order, performed by any leading system that exerts influence on the execution system in order to establish missions and fulfill them. When formulating and delimiting the functions of logistics support management we must consider the following:

- functions are actions performed by any logistics management system;
- the component actions of the logistics management functions take place one after the other in a well-defined time sequence;

- the functions are well defined and consequently relatively independent;

- the component actions are in constant dynamics, they change under the influence of some factors.

The logistics units of the military units in peacetime have closer links and increasingly cooperation with existing logistical companies in order to apply and benefit from advanced business practices, distribution processes, materials, as well as networks and flows specific to the logistics domain, in other words, the know-how of practical ability, knowledge and skill in a domain of interest.

In our opinion, the management of logistics support must perform the following functions: diagnosis; forecast; organization; command; coordination and control.

\subsection{Diagnosis}

Diagnosis is a function of logistics support management, a complex action, carried out after a certain algorithm, with specific methods and techniques of real data knowledge of military structures. Knowing the reality of the military units in peacetime in all its aspects, both positive and negative, becomes an essential condition for the logistics support activity.

Diagnosis is a directional, realistic and critical investigation of the process of logistics support and material supply for forces participating in training exercises, consisting of collecting raw data, studying them in order to transform the significant information needed for the adoption of the Logistics Activities Plan that underlie the drawing up the Main Activities Plan of each military unit.

We appreciate that the diagnosis is useful for all logistics modules leaders because it provides necessary information to understand the real status, allows for a 
critical reflection on the processes and their possible development, suggests inputs for the future developing of military activities and the establishment of the follow-up measures, to choose the ways and means to achieve the intended objectives.

\subsection{Prediction}

The prediction, as a basic function of logistics management, consists of an overall actions which determine the main (long, medium or short) objectives of logistics and the necessary resources and means.

Referring to the prediction, General A. Beaufre stated that "it is not the present but the future, today we are constrained to live in the future if we do not want it to be built by chance" (Beaufre, 1974, p. 51). Foresight is necessary to determine the most likely evolution of logistics support situation to know what decision is to be made, after the activity has started as well, in order to properly identify the possible unconventional changes preventing therefore disadvantageous effects. In other words, a good prediction supposes to identify possible consequences of the decisional alternative, aiming to lessen costs, maximizing the advantages, avoiding the failure of the planned military activity.

Depending on the anticipated periods of time, from the point of view of the military organization logistics evolution, three types of logistically foreseeable activities are distinguished: forecasting, planning and scheduling. Their result is reflected in forecasts, plans and programs.

The logistics forecast is a long-term anticipation of the logistics evolution for a military organization with more than five years deadline analyses and is based on specific methods and procedures for investigating economic and technical processes. Prognosis is usually done by the logistics structures of the upper echelon, especially those at the strategic level.

The planning process of logistics, where most of the forecasting activities are completed, "is usually compiled on average terms (from one quarter to one year) and short terms (from one month to one quarter)" (Minculete, 2015, p.78).

In the logical sequence-determined by the levels, the volume, the value and the degree of a detailed predicted problem-we can associate to the forecast: a general assertion framework, materialized in prognoses and which is usually done at all levels, respectively strategic, operative and tactical; a more restrictive framework in terms of time tracking evolutions of the analyzed phenomena embodied in the plans and which, as well as the forecasts, contain presumptions and a frame with a short time term, often the day or hour, materialized in the programs. We believe that the forecast covers the whole spectrum of logistics managerial activity from conception to execution, and exercised or carried out by the higher echelon and transmitted through the chain of command to lower level, ensures a unique conception in the logistics management structures and its ability to be perceived by the logistic execution structures.

\subsection{Organization}

The function of organizing the logistics of military units in peacetime involves the direct combination of human resources and, indirectly, material, informational and financial resources at the level of the management and logistic planning compartments, as well as for each job within the logistics structures.

Based on practical experience, we can state that an effective organization of logistics processes and activities must follow a number of specific requirements:

- to meet the requirements of normative acts in the logistics field;

be rational;

- to take into account the concrete situations and conditions in which military activities take place in peacetime;

ensure punctuality, spirit of responsibility, initiative, and order; 
- ensure the permanent reverse connection;

- ensure a fair and balanced allocation of logistical tasks;

- use their own organizational experience and other logistical echelons.

In the area of logistics activities we can talk about the structural organization, the organization of the military activities according to the Main Activities Plan (with the preparation and execution phases), as well as about the organization of the labor on each level of the logistics structures.

The logistics module is a balanced well-organized system within each employee who mans the departments, offices and logistics compartments determines, depending on their place and role, a system of organizational relationships, namely: authority (hierarchical-management, execution and information) functional; state-owned (large units and logistic units); cooperation and control.

We consider that the logistics processes and activities, synthetic named as procedural organization, is about adapting and implementation into reality all measures concerning the human, informational, technical, material and financial aspects of the respective military processes or activities, therefore all elements (the purpose, subject, object, sub-activities and tasks, resources, methods and working methods, conditions and deployment framework) have to be accomplished completely and detailed as much as possible for all personnel involved in their management and execution.

The field of organizing logistics activities has a special position in the understanding and manifestation of the organizational function. Therefore, we appreciate that this function is determined by the fact that in the military systems, the operational and logistic management processes consist, in essence, in the coordinated preparation and deployment of a large number of activities. They derive from the attributions of the respective logistic system and delimit the frame of manifestation of competence and responsibility of the cadres for the accomplishment of the elaborated logistic objectives and plans.

\subsection{Command}

Commanding the logistics military structures is the attribute of empowered commander leading to the "realization of a viable management system, as well as its efficient functioning, without disturbances and dysfunctions, with an increased adaptability, flexibility and flexibility which represents the guarantee of fulfilling the mission" (Pînzariu, 2017, p. 135) for each military entity, regardless of the hierarchical level. We assume that the order includes both authority and responsibility for the efficient use of logistical resources made available and for their planning, organization, coordination and control. This also implies responsibility for health, living standards, troop morale, and in the area of military exercises and ethics towards the local population.

In our opinion, the command of logistics units consists in transmitting the decision made by the head of the logistics to the subordinated logistics structures, and these structures, according to the specific tasks, take the necessary measures to implement it.

Within the logistics command, we distinguish two moments: order and motivation. By order, the head of logistics exerts direct influence on the subordinates, by virtue of the formal authority, training them in the accomplishment of their duties and obligations. Motivation denotes the strategy of action on the individual or group in order to act in a certain way. Motivation is also an essential lever in the individual behavioral self-regulation process, a driving force of his psychic and social development. We have to point out in this context that the following factors occur in the process of command: 
- the head of logistics with his authority and personality;

- the logistics structures of execution, respectively their subordinates, with their characteristics (profession, level of training, seniority, etc.);

- the tasks or issues to be solved.

The manner which the head of logistics influences the actions of others by command depends both on the certain situation and on his personality, experience and the degree of knowing his subordinates.

The practice of our work in different military structures, as well as the results of some controls and inspections I have performed, reveals some pragmatic ideas and principles that can help any head of logistics, regardless of hierarchical level, to ensure the functionality of the team leadership, such as:

- the appointment of people in the logistics positions must be exclusively on the basis of competence, morality and performance. Any deviation from this fundamental principle of human resources generates frustrations and resentments, conflicts and dissatisfactions, affects the inter-human relations and efficiency of logistics processes and activities;

- recognizing the value of collaborators and subordinates, by assessment the results achieved based on current standards, by preventing the phenomena of favoritism, bias and subjectivity in evaluation the quality and the outcome of work in the logistics field;

- timely and fair reporting on all matters relating to the evolution of military units in peacetime, ensuring consistent and ascending and descending communication with a useful content to carry out the tasks entrusted to them;

- accepting and stimulating the critical spirit, the concern to improve and optimize the selection and training structures, the endowment, the style and methods of work, the prompt and public highlighting of ideas and innovative solutions of their authors;
- the open and timely approach to conflictual issues of various genres that may arise, as in any human community. Homogeneity, cohesion, inner harmony does not mean "eye closure", indifference to some dysfunctions, reciprocal misgivings and compromises, concessions to violation of principles, but their courageous bringing to light and their prompt clarification precisely to avoid amplification and weakening of unity the leadership and execution teams in the logistics system of each military unit;

- timely annihilation of potential centrifugal tendencies, division into subgroups of trustworthy people, closeness of the head of logistics and marginalization, including by not engaging in tasks on various subjective motives of others, combating intolerance, participation and formal cooperation, envy and selfishness;

- real consultation, but not exhaustive, of the collaborators in the process of finding solutions, motivating and effectively engaging the logistics system in fulfilling what has been ordered or established by mutual agreement;

- obey the hierarchical principle for the orders transmitting through the leaders, and if it was not possible to do so, they should be informed as soon as possible in order to not affect their authority in front of the subordinates and not to remove them from the chain of command;

- cultivating sentimental, individual and collective emotional states, such as satisfaction, joy, recognition of "well-done work", optimism, trust and friendship that facilitate participation in leadership and generate new energies; eliminating asthenic affective states such as anxiety, inferiority complex, fear, mistrust, uncertainty that hinders, inhibits participation in the activities of the logistics team, and diminishes the motivation of involvement;

- overcoming transition periods, structural changes, failures, difficulties with calmness 
and lucidity, because the strength and cohesion of the logistics management team is manifested in such moments. From this point of view, it is totally counterproductive to escape responsibility, mutual accusations, search for causes outside the system, especially leadership, or the scapegoat policy, usually found guilty among the executors;

- appreciating merits and successes while emphasizing the importance of the spirit of camaraderie, cooperation and conjugation of efforts to accomplish tasks, thus balancing the relations between $I$ and we within the logistics management team.

\subsection{Coordination}

The role of logistics coordination is to maintain, preserve and improve the ordering status of the leading system and subordinate one, all the relations between them, as well as their synchronization with the other structures they come into contact with. The place of coordination lies between conception and logistics execution; its role is manifested both after the adoption of the logistical decision and especially during its application, without excluding its presence in the previous stage, during the elaboration of annual plans, monthly with the logistic activities.

We appreciate that, depending on the moment of realization, the coordination within the logistics management process has the following conditions of manifestation:

- it has its own dynamics;

- it is achieved, maintained and even restored when damaged;

- it assumes that the logistics activities have been prepared and planned;

- must refer to each hierarchical level (own and subordinate at least one step below), so that logistical coordination is achieved both horizontally and vertically.

We believe that the coordinating action ensures the adaptation of logistics to the conditions existing at every moment of its evolution, "but at the same time, the logistics system of the military units must be flexible, react quickly and efficiently in providing logistics support for the properly developing of the military activities planned under the Plan of Main Activities" (Pînzariu \& Mînea, 2019, p. 20). Simultaneously, by coordination, the actions of the logistics officers, the decisions issued at the different logistics management echelons, the actions of the entire logistics personnel within the planning and logistic management compartments are synchronized, in order to carry out effective activities, capable of achieving the predetermined logistics objectives. In our opinion, logistics coordination of military units in peacetime is about to carry out those activities that enable the head of logistics to actively and continuously intervene in its various components.

We appreciate that the coordination action may be, depending on the way of implementation, bilateral-when it is run between the head of the logistics planning and logistics departments and a certain subordinate and multilateral-when is floating between the head of logistics and several subordinates or all subordinates.

For a solid logistics coordination, we believe that the following conditions must be met:

- the proper functioning of the relationalcommunication system between the components of the logistics, between personnel, logistics managers and the subordinates, in order to adopt the necessary changes;

- the judicious allocation of decisions at all levels of military logistics and the widespread use of delegation of authority;

- correct understanding of motivation;

- appropriate selection and training of logistics staff and contract civilian staff. 
Each logistics management cycle ends with control, evaluation and adjustment activities designed to bring information to the commander about how the structure's objectives are being achieved and to support new managerial decisions. The controlevaluation-adjustment function includes all the actions for tracking of how logistics missions are performed, to determine their deviation from the adopted course, to identify the causes that generated it and adopting complementary measures to ensure the elimination of deviations or, in other words, all the specific activities which assess the logistics compartment (or similar) performance or by different structures subordinated to it, in a given time, compared to the intended objectives, to prompt intervention in case of possible abnormalities or shortcomings in their realization.

We can assert that the control determines the way of ensuring the legality and the achievement of the performance levels, by reference to the provisions, standards and/or requirements contained in the normative acts that regulate different fields of activity. Inspections can identify the system dysfunctions and fix them by modifying or issuing normative acts. Control has a well-defined purpose, is coordinated, instructive, and ends with an objective and substantiated control report.

We need to emphasize that control in logistics area must focus on guidance and improvement, has an instructive-educational character, and do not simply focus on whether the controlled activity is satisfactory or not. From practical experience, we can state that the bodies responsible for exercising control of the military organization, apart from the fact, must also take into account the situations that have led to undesirable phenomena and, first of all, to appreciate the entire activity of the structural chain, the compartment, the collective, the subordinate performer as a whole and not to be limited to isolated facts, disrupted by the connection between cause and effect.
Therefore, the logistics control function must be understood in all its complexity, not for purposes of justification, but in the interest of a realistic analysis of the phenomenon. In the process of conducting control, the leaders need to know precisely the tasks of controlled person, to have the ability to distinguish the essence, to take a picture of the difficulties in fulfilling the tasks, the stages through which a problem passes until it is solved and situations where the most common mistakes are made. Control becomes effective through the effectiveness of its results, rather than by resortin to sanctions.

At the same time, we consider that the management of logistics support involves qualified and experienced personnel for the successful accomplishment of logistics support missions regardless of the nature of the specific military activities and the planned military exercises but also involves financial and material support, as well as a modern infrastructure.

That is why we appreciate that the logistics support becomes the fundamental design of specific military activities and military training exercises, resulting in a recognized requirement: good military planning implies that the objectives of the military exercises are set so that they are in line with the level of logistics support, as the main criterion pursued in the logistics support of the military structures is the achievement of high efficiency.

Our conclusion is that the general manager is the commander and the logistics managerial processes are the responsibility of the logistics chief manager with delegated authority of the commander and the requirements of his function. The general tendency is to separate operational and administrative management from the logistics problems of managers/ commanders, which necessitates an urgent need to ensure all conditions for the management of logistics support to form a system with its own operating autonomy, able to interrelate with other systems. 


\section{Conclusions}

Within the logistics support of the military units in peacetime, by approaching the functions of logistics support of military activities we highlighted the implications, the multiple determinations and the particularities of their implementation in the logistics support training activities and the combat forces training during peacetime as well. The key factor is understanding the interdependence between logistics support management functions and planned logistics objectives, and the fact that they are mutually conditioned, requires constant adaptation and development to match as fully as possible the application and use possibilities in achieving the objectives proposed. That is why we believe that logistics support management functions can be applied in all situations, namely peace, multinational operations, crisis, mobilization and war.

As a final conclusion, we believe that the widening of the spectrum of joint military actions tailored to the requirements of the NATO has generated the approach of logistics management functions in accordance with the missions and tasks of combat forces during the peacetime. In this sense, we consider that the logistics support for training activities, as well as the logistics support underlying the constitution of war material stocks, depend on the unitary application of the logistics support management functions these ideas being partly found in logistics doctrines and have been deepened by different specialists, but has been implemented only in multinational operations and in crisis, mobilization and war situations. In this respect, we propose a clear stipulation of logistics support management functions in the existing logistics instructions and regulations for training of military units, closely correlated with those applicable during multinational operations or crisis, mobilization and war situations as well.

\section{REFERENCES}

Beaufre, A. (1974). Introduction to Strategy. Action Strategy. Bucharest: Military Publishing House.

Minculete, Ghe. (2003). Logistic Management-Concepts-Functions-Applications. Bucharest: Academy of High Military Studies.

Minculete, Ghe. (2005). Logistics Support Management Elements. Bucharest: "Carol I" National Defense University Publishing House.

Minculete, Ghe. (2015). Modern Approaches of Logistics Management. Bucharest: "Carol I" National Defense University Publishing House.

Nicolescu, O., \& Verboncu, I. (1997). Management. Bucharest: Economic Publishing House.

Pînzariu, S. (2005). Logistics Support Leadership in Multinational Operations. Bucharest: "Carol I" National Defense University Publishing House.

Pînzariu, S. (2017). Multinational Operations under command and leadership of the UN. Bulletin of "Carol I" National Defense University, No. 2, Bucharest: "Carol I" National Defense University Publishing House.

Pînzariu, S., \& Mînea, D. (2019). Principles of logistic support of military units at peace. Sibiu: "Nicolae Bălcescu” Land Forces Academy. 